Provided for non-commercial research and education use. Not for reproduction, distribution or commercial use.

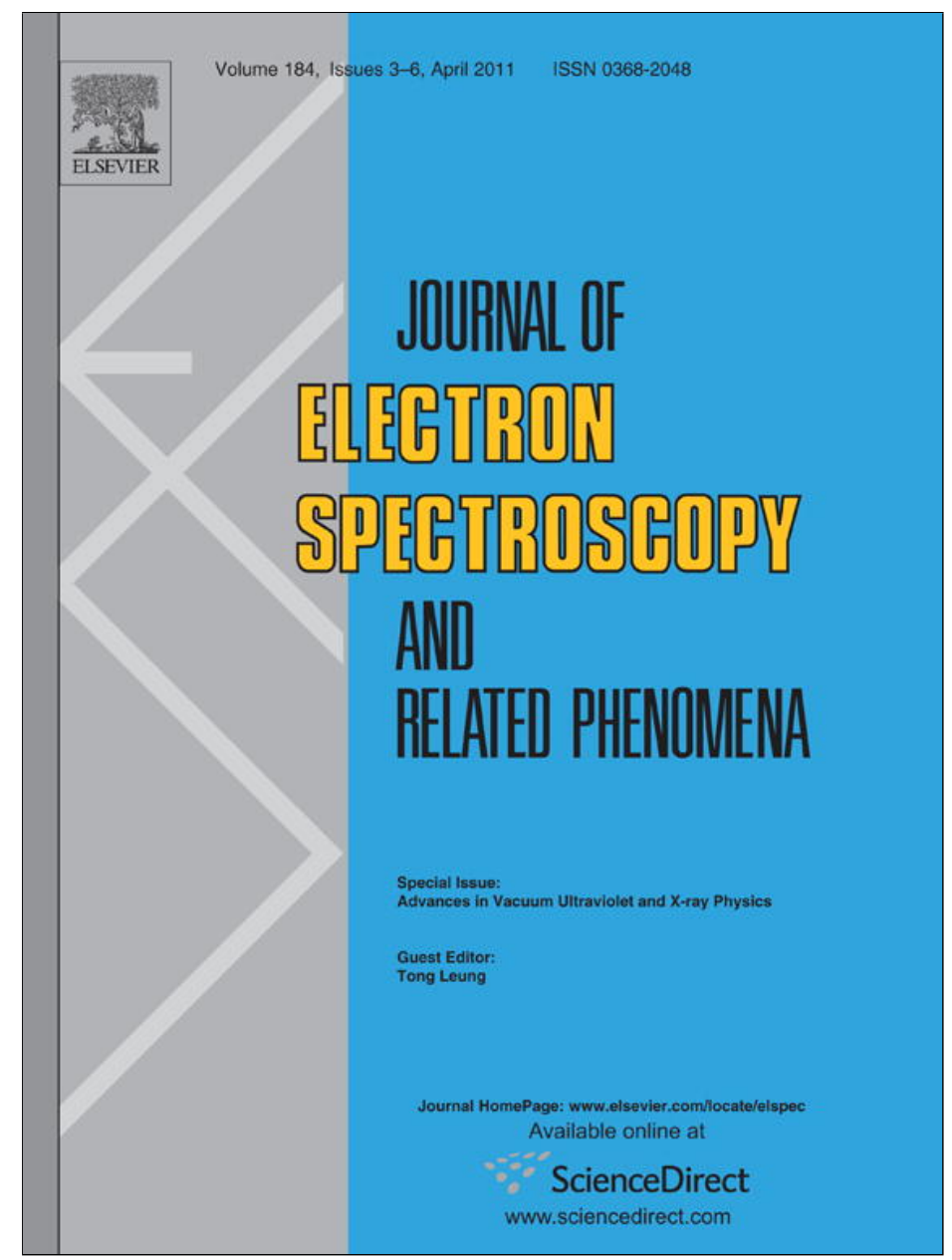

This article appeared in a journal published by Elsevier. The attached copy is furnished to the author for internal non-commercial research and education use, including for instruction at the authors institution and sharing with colleagues.

Other uses, including reproduction and distribution, or selling or licensing copies, or posting to personal, institutional or third party websites are prohibited.

In most cases authors are permitted to post their version of the article (e.g. in Word or Tex form) to their personal website or institutional repository. Authors requiring further information regarding Elsevier's archiving and manuscript policies are encouraged to visit:

http://www.elsevier.com/copyright 


\title{
Atomic data for VUV lines of astrophysical interest in singly ionized rhodium
}

\author{
P. Quinet ${ }^{\mathrm{a}, \mathrm{b}, *}$, É. Biémont $^{\mathrm{a}, \mathrm{b}}$, P. Palmeri ${ }^{\mathrm{a}}$, L. Engström ${ }^{\mathrm{c}}$, H. Hartman $^{\mathrm{d}}$, H. Lundberg $^{\mathrm{c}}$, H. Nilsson $^{\mathrm{d}}$ \\ a Astrophysique et Spectroscopie, Université de Mons - UMONS, B-7000 Mons, Belgium \\ b IPNAS, B15 Sart Tilman, Université de Liège, B-4000 Liège, Belgium \\ c Department of Physics, Lund University, PO Box 118, SE-221 00 Lund, Sweden \\ ${ }^{\mathrm{d}}$ Lund Observatory, Lund University, PO Box 43, SE-221 00 Lund, Sweden
}

\section{A R T I C L E I N F O}

\section{Article history:}

Available online 27 August 2010

\section{Keywords:}

Electronic structure

Oscillator strengths

Transition probabilities

Radiative lifetimes

\begin{abstract}
A B S T R A C T
The first theoretical transition probabilities and oscillator strengths are reported for Rh II lines of astrophysical interest in the VUV region $(100-200 \mathrm{~nm})$. They have been obtained through the use of a pseudo-relativistic Hartree-Fock model including core-polarization effects and the accuracy has been estimated to be about $10-15 \%$ through a comparison with new experimental lifetimes measured using the time-resolved laser-induced fluorescence technique.
\end{abstract}

(C) 2010 Elsevier B.V. All rights reserved.

\section{Introduction}

In astrophysics, there is a growing need for spectroscopic data concerning neutral and lowly ionized heavy atoms $(Z \geq 37)$ arising mostly from investigation of the atmospheres of chemically peculiar (CP) stars. Atomic data, such as wavelengths, line intensities, transition probabilities and oscillator strengths, are important for computing the opacity of the stellar matter and, consequently, for building models of the stars. In addition, they are essential for deriving abundances from the equivalent widths or line profiles of the observed lines. In particular, the understanding of the large overabundances of some elements in CP stars related to diffusion processes and magnetic field effects, requires a large number of fundamental radiative paramaters for neutral, singly and doubly ionized heavy elements $[1,2]$.

In stellar nucleosynthesis, a detailed analysis of the $r$ - and $s$ processes is not possible without accurate atomic data not only for the prominent stellar lines but also for a huge number of weak absorption features which are now observable on the high resolution spectra available both from ground and space observatories in the whole range of the electomagnetic spectrum [1].

In this context, the determination and accuracy of the spectroscopic data for a large number of heavy atoms and ions is of key importance. Although many are now available from modern experimental techniques or sophisticated theoretical methods, they are still insufficient to meet all the needs of the astrophysical commu-

\footnotetext{
* Corresponding author at: Astrophysique et Spectroscopie, Université de Mons - UMONS, B-7000 Mons, Belgium. Tel.: +32 0653736 27; fax: +32 065373629.

E-mail address: quinet@umons.ac.be (P. Quinet).
}

nity. This is particularly true for singly ionized rhodium for which no radiative data have been published so far in the literature despite the fact that Rh II lines have been identified in different astrophysical spectra such as the spectra of the HgMn type star $\chi$ Lupi [3], the super-rich mercury star HD 65949, the HgMn star HD 175640 and the peculiar Przybylski's star HD 101065 [4].

In the present paper, we report on new theoretical transition rates for VUV Rh II lines obtained within the framework of the relativistic Hartree-Fock (HFR) approach [5] including core-polarization effects. The reliability of these results has been assessed through a comparison with experimental radiative lifetimes measured for some selected levels using the time-resolved laser-fluorescence technique at the Lund High Power Laser Facility, Sweden.

This work is part of an extensive program of radiative rate measurements and calculations for heavy atoms and ions belonging to the fifth and the sixth rows of the periodic table.

\section{Atomic structure calculations}

Calculations of energy levels and radiative transition rates in $\mathrm{Rh}$ II have been carried out using the relativistic Hartree-Fock (HFR) approach [5] modified to take core-polarization effects into account (see e.g. Refs. [6,7]). This method (HFR + CPOL) has been combined with a least-squares optimization process of the radial parameters in order to reduce the discrepancies between the Hamiltonian eigenvalues and the available experimental energy levels.

The following configurations were explicitly introduced in the calculations: $4 d^{8}+4 d^{7} 5 s+4 d^{7} 6 s+4 d^{7} 5 d+4 d^{7} 6 d+4 d^{6} 5 s^{2}+$ $4 d^{6} 5 p^{2}+4 d^{6} 5 d^{2}+4 d^{6} 5 s 6 s+4 d^{6} 5 s 5 d+4 d^{6} 5 s 6 d$ and $4 d^{7} 5 p+$ $4 d^{7} 6 p+4 d^{7} 4 f+4 d^{7} 5 f+4 d^{6} 5 s 5 p+4 d^{6} 5 s 6 p+4 d^{6} 5 p 5 d+4 d^{6} 5 p 6 s$ 
for the even and odd parities, respectively. This configuration list extends considerably the one considered in the previous theoretical investigation of Rh II due to Shadmi [8] who limited the calculations to the $4 d^{8}+4 d^{7} 5 s+4 d^{6} 5 s^{2}$ configurations. The ionic core considered for the core-polarization model potential and the correction to the transition dipole operator was a $4 \mathrm{~d}^{6} \mathrm{Rh}$ IV Mo-like core. The dipole polarizability, $\alpha_{d}$, for such a core is 4.79 $\mathrm{a}_{0}{ }^{3}$ according to Fraga et al. [9]. We used the HFR mean value $\langle r\rangle$ of the outermost $4 \mathrm{~d}$ core orbital, $1.52 \mathrm{a}_{0}$, for the cut-off radius, $r_{c}$.
Table 1

Experimental and calculated lifetimes obtained in the present work for five levels within the $4 \mathrm{~d}^{7}\left({ }^{4} \mathrm{~F}\right) 5 \mathrm{p}$ configuration of Rh II.

\begin{tabular}{llll}
\hline Level & $E^{\mathrm{a}}\left(\mathrm{cm}^{-1}\right)$ & $\tau_{\exp }(\mathrm{ns})$ & $\tau_{\text {calc }}(\mathrm{ns})$ \\
\hline $\mathrm{z}^{5} \mathrm{~F}_{4}{ }^{\circ}$ & 56547.3 & $3.9 \pm 0.5$ & 4.4 \\
$\mathrm{z}^{5} \mathrm{D}_{4}^{\circ}$ & 59161.5 & $3.3 \pm 0.2$ & 3.9 \\
$\mathrm{z}^{5} \mathrm{G}_{6}^{\circ}$ & 59702.4 & $3.0 \pm 0.2$ & 3.1 \\
$\mathrm{z}^{3} \mathrm{G}_{5}^{\circ}$ & 62194.4 & $3.2 \pm 0.2$ & 3.5 \\
$\mathrm{z}^{3} \mathrm{~F}_{4}^{\circ}$ & 62326.1 & $2.4 \pm 0.2$ & 2.8 \\
\hline
\end{tabular}

a From Ref. [10].

Table 2

Transition probabilities and oscillator strengths calculated in the present work for selected Rh II lines in the VUV region between 100 and 200 nm. Only transitions with $\log g f>-1.0$ are given. $X(Y)$ stands for $X \times 10^{Y}$.

\begin{tabular}{|c|c|c|c|c|c|c|c|}
\hline \multirow[t]{2}{*}{$\lambda^{\mathrm{a}}(\mathrm{nm})$} & \multirow[t]{2}{*}{ Int. $^{a}$} & \multicolumn{2}{|c|}{ Lower level $^{\mathrm{a}}$} & \multicolumn{2}{|c|}{ Upper level $^{\mathrm{a}}$} & \multirow[t]{2}{*}{$\log g f$} & \multirow[t]{2}{*}{$g A\left(\mathrm{~s}^{-1}\right)$} \\
\hline & & $E\left(\mathrm{~cm}^{-1}\right)$ & Desig. & $E\left(\mathrm{~cm}^{-1}\right)$ & Desig. & & \\
\hline 126.216 & 40 & 8164.4 & $a{ }^{1} D_{2}$ & 87394.0 & $\mathrm{v}^{3} \mathrm{D}_{3}^{\circ}$ & -0.55 & $1.18(9)$ \\
\hline 128.465 & 60 & 0.0 & $\mathrm{a}^{3} \mathrm{~F}_{4}$ & 77842.8 & $\mathrm{x}^{3} \mathrm{~F}_{4}^{\circ}$ & -0.91 & $5.04(8)$ \\
\hline 129.174 & 40 & 10515.0 & $a^{3} P_{1}$ & 87930.1 & $\mathrm{v}^{3} \mathrm{D}_{2}^{\circ}$ & -0.68 & $8.34(8)$ \\
\hline 129.761 & 20 & 10760.8 & $a^{3} P_{0}$ & 87827.5 & $\mathrm{v}^{3} \mathrm{D}_{1}^{\circ}$ & -0.99 & $4.01(8)$ \\
\hline $131.085^{*}$ & & 11643.7 & $a^{3} P_{2}$ & 87930.1 & $\mathrm{v}^{3} \mathrm{D}_{2}^{\circ}$ & -0.81 & $6.05(8)$ \\
\hline 131.523 & 90 & 0.0 & $a^{3} F_{4}$ & 76032.4 & $w^{3} \mathrm{D}_{3}^{\circ}$ & -0.20 & $2.46(9)$ \\
\hline 131.636 & 50 & 3580.7 & $a^{3} F_{2}$ & 79547.6 & $\mathrm{z}^{1} \mathrm{P}_{1}^{\circ}$ & -0.86 & $5.28(8)$ \\
\hline 131.747 & 50 & 2401.3 & $a^{3} F_{3}$ & 78303.9 & $\mathrm{x}^{3} \mathrm{~F}_{2}^{\circ}$ & -0.65 & $8.59(8)$ \\
\hline 132.012 & 40 & 11643.7 & $a^{3} P_{2}$ & 87394.0 & $\mathrm{v}^{3} \mathrm{D}_{3}^{\circ}$ 。 & -0.68 & $7.90(8)$ \\
\hline 133.830 & 50 & 3580.7 & $a^{3} F_{2}$ & 78303.9 & $x^{3} F_{2}^{\circ}$ & -0.72 & $7.07(8)$ \\
\hline 134.213 & 200 & 0.0 & $a^{3} F_{4}$ & 74509.8 & $\mathrm{y}^{3} \mathrm{G}_{5}^{\circ}$ & 0.10 & $4.62(9)$ \\
\hline 134.947 & 100 & 2401.3 & $a^{3} F_{3}$ & 76504.5 & $\mathrm{x}^{3} \mathrm{G}_{4}^{\circ}$ & -0.02 & $3.50(9)$ \\
\hline 135.041 & 50 & 3580.7 & $a^{3} F_{2}$ & 77633.0 & $\mathrm{x}^{3} \mathrm{D}_{1}^{\circ}$ & -0.73 & $6.76(8)$ \\
\hline 135.110 & 60 & 3580.7 & $a^{3} F_{2}$ & 77595.0 & $\mathrm{x}^{3} \mathrm{G}_{3}^{\circ}$ & -0.29 & $1.86(9)$ \\
\hline 135.811 & 50 & 2401.3 & $a^{3} F_{3}$ & 76032.4 & $w^{3} D_{3}{ }^{\circ}$ & -0.90 & $4.52(8)$ \\
\hline 135.824 & 40 & 8164.4 & a ${ }^{1} D_{2}$ & 81788.9 & $\mathrm{y}^{1} \mathrm{~F}_{3}{ }^{\circ}$ & -0.77 & $6.18(8)$ \\
\hline 135.860 & 50 & 2401.3 & $a^{3} F_{3}$ & 76007.3 & $w^{3} D_{2}{ }^{\circ}$ & -0.41 & 1.41(9) \\
\hline 136.444 & 10 & 2401.3 & $a^{3} F_{3}$ & 75691.1 & $x^{3} D_{3}^{\circ}$ & -0.84 & $5.24(8)$ \\
\hline 137.231 & 80 & 0.0 & $a^{3} F_{4}$ & 72870.6 & $\mathrm{z}^{1} \mathrm{G}_{4}^{\circ}$ & -0.41 & $1.38(9)$ \\
\hline 138.307 & 30 & 0.0 & $\mathrm{a}^{3} \mathrm{~F}_{4}$ & 72303.7 & $\mathrm{y}^{3} \mathrm{~F}_{3}$ 。 & -0.86 & $4.82(8)$ \\
\hline 138.962 & 10 & 2401.3 & $a^{3} F_{3}$ & 74364.4 & $\mathrm{z}^{1} \mathrm{~F}_{3}{ }^{\circ}$ & -0.93 & $4.10(8)$ \\
\hline 139.326 & 30 & 8164.4 & $a{ }^{1} D_{2}$ & 79938.8 & $\mathrm{y}^{1} \mathrm{D}_{2}^{\circ}$ & -0.62 & $8.18(8)$ \\
\hline 139.652 & 30 & 11643.7 & $a^{3} P_{2}$ & 83251.4 & $\mathrm{x}^{3} \mathrm{P}_{1}^{\circ}$ & -0.41 & $1.32(9)$ \\
\hline 139.718 & 50 & 3580.7 & $\mathrm{a}^{3} \mathrm{~F}_{2}$ & 75152.4 & $\mathrm{y}^{3} \mathrm{~F}_{2}$ 。 & -0.44 & $1.24(9)$ \\
\hline 139.757 & 20 & 8164.4 & $a{ }^{1} D_{2}$ & 79717.5 & $\mathrm{z}^{1} \mathrm{D}_{2}^{\circ}$ & -0.90 & $4.29(8)$ \\
\hline 140.834 & 90 & 0.0 & $a^{3} F_{4}$ & 71005.7 & $\mathrm{y}^{5} \mathrm{D}_{4}{ }^{\circ}$ & -0.25 & 1.91(9) \\
\hline \multirow[t]{2}{*}{$141.274^{\mathrm{b}}$} & 100 & 2401.3 & $a^{3} F_{3}$ & 73185.7 & $\mathrm{y}^{3} \mathrm{D}_{3}^{\circ}$ & -0.40 & $1.34(9)$ \\
\hline & & 3580.7 & $a^{3} F_{2}$ & 74364.4 & $\mathrm{z}^{1} \mathrm{~F}_{3}{ }^{\circ}$ & -0.58 & $8.74(8)$ \\
\hline 142.224 & 80 & 11643.7 & $a^{3} P_{2}$ & 81955.0 & $\mathrm{x}^{3} \mathrm{P}_{2}^{\circ}$ & -0.11 & $2.59(9)$ \\
\hline 142.573 & 20 & 8164.4 & $a{ }^{1} D_{2}$ & 78303.9 & $\mathrm{x}^{3} \mathrm{~F}_{2}{ }^{\circ}$ & -0.93 & $3.85(8)$ \\
\hline 144.041 & 20 & 10515.0 & $a^{3} P_{1}$ & 79938.8 & $\mathrm{y}^{1} \mathrm{D}_{2}{ }^{\circ}$ & -0.87 & $4.33(8)$ \\
\hline 147.110 & 100 & 14855.4 & $a^{1} G_{4}$ & 82830.7 & $\mathrm{y}^{1} \mathrm{H}_{5}{ }^{\circ}$ & -0.12 & $2.34(9)$ \\
\hline 148.091 & 20 & 8164.4 & $a{ }^{1} D_{2}$ & 75691.1 & $\mathrm{x}^{3} \mathrm{D}_{3}^{\circ}$ & -0.98 & $3.20(8)$ \\
\hline 148.118 & 80 & 11643.7 & $a^{3} P_{2}$ & 79159.7 & $\mathrm{x}^{3} \mathrm{~F}_{3}^{\circ}$ & -0.41 & $1.17(9)$ \\
\hline 149.403 & 40 & 14855.4 & $\mathrm{a}^{1} \mathrm{G}_{4}$ & 81788.9 & $\mathrm{y}^{1} \mathrm{~F}_{3}{ }^{\circ}$ & -0.62 & $7.14(8)$ \\
\hline 150.074 & 100 & 14855.4 & $a{ }^{1} G_{4}$ & 81488.5 & $\mathrm{y}^{1} \mathrm{G}_{4}$ 。 & 0.16 & 4.31(9) \\
\hline 150.664 & 50 & 8164.4 & $a{ }^{1} D_{2}$ & 74537.8 & $\mathrm{y}^{3} \mathrm{P}_{1}^{\circ}$ & -0.97 & $3.12(8)$ \\
\hline 151.059 & 50 & 8164.4 & $a{ }^{1} D_{2}$ & 74364.4 & $\mathrm{z}^{1} \mathrm{~F}_{3}^{\circ}$ & -0.94 & $3.34(8)$ \\
\hline 151.398 & 50 & 10515.0 & $a^{3} P_{1}$ & 76566.6 & $\mathrm{x}^{3} \mathrm{D}_{2}^{\circ}$ & -0.89 & $3.72(8)$ \\
\hline 152.543 & 50 & 8164.4 & a ${ }^{1} D_{2}$ & 73720.1 & $\mathrm{y}^{3} \mathrm{P}_{2}{ }^{\circ}$ & -0.88 & $3.81(8)$ \\
\hline 152.909 & 60 & 14855.4 & $a^{1} G_{4}$ & 80254.0 & $\mathrm{y}^{3} \mathrm{H}_{4}^{\circ}$ & -0.92 & $3.43(8)$ \\
\hline 153.091 & 100 & 0.0 & $a^{3} F_{4}$ & 65321.2 & $\mathrm{z}^{3} \mathrm{G}_{3}^{\circ}$ & -0.52 & $8.55(8)$ \\
\hline 154.274 & 100 & 0.0 & $a^{3} F_{4}$ & 64819.4 & $\mathrm{z}^{3} \mathrm{D}_{3}^{\circ}$ 。 & -0.72 & $5.31(8)$ \\
\hline 154.933 & 50 & 14855.4 & $\mathrm{a}^{1} \mathrm{G}_{4}$ & 79399.3 & $\mathrm{y}^{3} \mathrm{H}_{5}^{\circ}$ & -0.86 & $3.82(8)$ \\
\hline 155.510 & 90 & 14855.4 & $\mathrm{a}^{1} \mathrm{G}_{4}$ & 79159.7 & $\mathrm{x}^{3} \mathrm{~F}_{3}$ 。 & -0.83 & $4.04(8)$ \\
\hline 157.041 & 100 & 2401.3 & $a^{3} F_{3}$ & 66078.8 & $\mathrm{z}^{3} \mathrm{D}_{2}^{\circ}$ & -0.49 & $8.70(8)$ \\
\hline 158.257 & 90 & 3580.7 & $a^{3} F_{2}$ & 66769.7 & $\mathrm{z}^{3} \mathrm{D}_{1}$ 。 & -0.77 & $4.58(8)$ \\
\hline 158.400 & 90 & 10515.0 & $\mathrm{a}^{3} \mathrm{P}_{1}$ & 73646.3 & $\mathrm{z}^{1} \mathrm{P}_{1}^{\circ}$ & -0.59 & $6.96(8)$ \\
\hline 159.435 & 100 & 11643.7 & $a^{3} P_{2}$ & 74364.4 & $\mathrm{z}^{1} \mathrm{~F}_{3}^{\circ}$ & -0.73 & $4.93(8)$ \\
\hline 160.445 & 500 & 0.0 & $a^{3} F_{4}$ & 62326.1 & $\mathrm{z}^{3} \mathrm{~F}_{4}^{\circ}$ & -0.36 & $1.14(9)$ \\
\hline 162.894 & 500 & 3580.7 & $a^{3} F_{2}$ & 64970.4 & $\mathrm{z}^{3} \mathrm{~F}_{2}{ }^{\circ}$ & -0.60 & $6.32(8)$ \\
\hline 163.472 & 200 & 0.0 & $a^{3} F_{4}$ & 61173.1 & $\mathrm{z}^{5} \mathrm{G}_{4}^{\circ}$ & -0.96 & $2.76(8)$ \\
\hline 163.788 & 200 & 2401.3 & $a^{3} F_{3}$ & 63454.9 & $z^{3} F_{3}^{\circ}$ & -0.57 & $6.72(8)$ \\
\hline 166.717 & 20 & 14855.4 & a ${ }^{1} G_{4}$ & 74836.2 & $\mathrm{z}^{1} \mathrm{H}_{5}^{\circ}$ & -0.79 & $3.94(8)$ \\
\hline 168.041 & 90 & 14855.4 & $a^{1} G_{4}$ & 74364.4 & $\mathrm{z}^{1} \mathrm{~F}_{3}$ 。 & -0.99 & $2.43(8)$ \\
\hline 170.680 & 80 & 14855.4 & $a^{1} G_{4}$ & 73444.3 & $\mathrm{y}^{3} \mathrm{G}_{5}$ 。 & -0.93 & $2.70(8)$ \\
\hline 176.509 & 80 & 8164.4 & a ${ }^{1} D_{2}$ & 64819.4 & $\mathrm{z}^{3} \mathrm{D}_{3}^{\circ}$ & -0.89 & $2.74(8)$ \\
\hline 179.974 & 80 & 10515.0 & $a^{3} P_{1}$ & 66078.8 & $z^{3} D_{2}^{\circ}$ & -0.89 & 2.63(8) \\
\hline
\end{tabular}

* Wavelength deduced from experimental levels from Ref. [10].

a From Ref. [10]. Note that some strong Rh II lines were also reported in Ref. [14].

b Blend. 
In addition, the calculated eigenvalues of the Hamiltonian were adjusted to the experimental energy levels from Ref. [10]. For the $4 d^{8}, 4 d^{7} 5 s$ and $4 d^{7} 5 p$ configurations, the average energies $\left(E_{a v}\right)$, the electrostatic direct $\left(F^{k}\right)$ and exchange $\left(G^{k}\right)$ integrals, the spin-orbit $\left(\zeta_{n l}\right)$ and the effective interaction $(\alpha)$ parameters were allowed to vary during the fitting process. Further more, an additional effective operator $(\beta)$ for the $4 d^{7} 5 s$ configuration was included in the adjustment. All other Slater integrals were scaled down by a factor 0.85 following a well-established procedure [5]. The standard deviations of the fits were $50 \mathrm{~cm}^{-1}$ for the even parity and $111 \mathrm{~cm}^{-1}$ for the odd parity. Note that the even level at $35012.0 \mathrm{~cm}^{-1}$ had to be excluded from the fit because its designation as $4 d^{7}\left({ }^{2} \mathrm{P}\right) 5 \mathrm{~s} \mathrm{~b}^{3} \mathrm{P}_{0}$ given in Ref. [10] appeared questionable. Our HFR predicted eigenvalue for this state was found to be more than $1000 \mathrm{~cm}^{-1}$ above the experimental value.

\section{Radiative lifetime measurements}

In order to assess the accuracy of the calculations, comparisons with experimental results have been performed. Radiative lifetimes for some selected Rh II levels have been measured using the time-resolved laser-induced fluorescence technique applied to a laser-produced plasma. The experimental setup used in the present experiment is the same as the one described in many previous papers (e.g. Refs. [11-13]). Consequently, only a brief description will be given here.

Two Q-switched Nd:YAG lasers were used in our experiment. One of them (Continuum Surelite), characterized by a 10 ns duration and a $2-10 \mathrm{~mJ}$ pulse energy at $532 \mathrm{~nm}$, was used as an ablation laser focused on a pure rhodium foil rotating in a $10^{-5}-10^{-6} \mathrm{mbar}$ vacuum chamber and to produce a plasma containing $\mathrm{Rh}^{+}$ions. The second Nd:YAG laser (Continuum NY-82) is an injection seeded laser and provides $8 \mathrm{~ns}$ pulse duration and $400 \mathrm{~mJ}$ pulse energy at $532 \mathrm{~nm}$. The laser beam was compressed to about $1-2 \mathrm{~ns}$ by a stimulated Brillouin scattering (SBS) compressor. These pulses were used to pump a dye laser (Continuum Nd-60) operating with a DCM dye. We used a KDP crystal and Raman shifting in a $\mathrm{H}_{2}$ cell to extend the tunable range of the laser radiation. The excitation pulse was sent horizontally into the vacuum chamber to interact with the plume about $10 \mathrm{~mm}$ above the foil. The ablation and the excitation pulses were synchronized by external triggering from a digital delay generator. The emitted fluoresence light was collected by a fused-silica lens, filtered by a $1 / 8 \mathrm{~m}$ monochromator and finally detected by a PMT microchannel plate (Hamamatsu R 1564) with a rise time of $160 \mathrm{ps}$. The excitation laser pulse was detected separately by a fast photodiode. Both signals were then recorded and averaged over 1000 pulses by a transient digitizer and transferred to a computer for the lifetime evaluations. The computer code DECFIT was used to analyze the fluorescence signals. Radiative lifetimes are extracted by a weighted least-squares fit of a single exponential decay convoluted with the shape of the laser pulse to the fluorescence signal. In addition, a polynomial background representation can be added in the fit.

During the experiment, about 10 curves were recorded for each level under different experimental conditions in order to minimize systematic errors and the averaged lifetime value was adopted as the final result.

\section{Results and discussion}

In Table 1, we present the experimental radiative lifetimes measured in the present work for 5 levels belonging to five different terms within the $4 d^{7}\left({ }^{4} \mathrm{~F}\right) 5 \mathrm{p}$ configuration, i.e. $\mathrm{z}^{5} \mathrm{~F}^{\circ}, \mathrm{z}^{5} \mathrm{D}^{\circ}, \mathrm{z}^{5} \mathrm{G}^{\circ}$, $\mathrm{z}^{3} \mathrm{G}^{\circ}$ and $\mathrm{z}^{3} \mathrm{~F}^{\circ}$. These values are compared with the theoretical results obtained using the HFR + CPOL model. As shown in this table, the over-all agreement between theory and experiment is very good. However, the HFR + CPOL results seem to be systematically $5-15 \%$ longer than the measurements.

Calculated oscillator strengths (log $g$ ) and transition probabilities $(g A)$ for Rh II lines in the VUV spectral region between 100 and $200 \mathrm{~nm}$ are reported in Table 2. Due to the large number of computed transitions in the present study, this table is restricted to the transitions with $\log g f \geq-1.0$. The complete table is available upon request to the authors. Based on the comparison between experimental and theoretical lifetimes in Table 1, we expect an accuracy of $10-15 \%$ for the new oscillator strengths and transition probabilities at least for the strongest transitions and for the transitions not affected by cancellation effects reported in Table 2 .

The present work will be extended to Rh II lines in the near UV and visible in a further paper.

\section{Acknowledgments}

This work was financially supported by the Integrated Initiative of Infrastructure Project LASERLAB-EUROPE, contract RII3-CT2003-506350, the Swedish Research Council through the Linnaeus grant, the Knut and Alice Wallenberg Foundation and the Belgian FRS-FNRS. EB, PQ and PP are, respectively, Research Director, Senior Research Associate and Research Associate of this latter organization.

\section{References}

[1] A. Jorissen, Phys. Scripta 112 (2004) 73.

[2] G. Wallerstein, et al., Rev. Mod. Phys. 69 (1997) 995.

[3] H. Lundberg, S. Johansson, U. Litzén, G.M. Wahlgren, S. Leckrone, ASP Conf. Ser. 143 (1998) 343.

[4] C.R. Cowley, http://www.astro.lsa.umich.edu/ cowley/, 2009.

[5] R.D. Cowan, The Theory of Atomic Structure and Spectra, University of California Press, Berkeley, 1981.

[6] P. Quinet, P. Palmeri, É. Biémont, M.M. McCurdy, G. Rieger, E.H. Pinnington, M.E. Wickliffe, J.E. Lawler, Mon. Not. R. Astron. Soc. 307 (1999) 934.

[7] P. Quinet, P. Palmeri, É. Biémont, Z.S. Li, Z.G. Zhang, S. Svanberg, J. Alloys Compd. 344 (2002) 255.

[8] Y. Shadmi, Bull. Res. Coun. Israel 9F (1961) 141

[9] S. Fraga, J. Karwowski, K.M.S. Saxena, Handbook of Atomic Data, Elsevier, Amsterdam, 1976.

[10] F.J. Sancho, Anales Real. Soc. Esp. Fis. y Quim. 54A (1958) 41.

[11] H. Bergström, H. Faris, G.W. Hallstadius, H. Lundberg, A. Persson, C.G. Wahlström, Z. Phys. D 8 (1988) 17.

[12] Z.G. Zhang, Z.S. Li, S. Svanberg, P. Palmeri, P. Quinet, É. Biémont, Eur. Phys. J. D 15 (2001) 301.

[13] H.L. Xu, A. Persson, S. Svanberg, K. Blagoev, G. Malcheva, V. Pentchev, E. Biémont, J. Campos, M. Ortiz, R. Mayo, Phys. Rev. A 70 (2004) 042508.

[14] J.E. Sansonetti, W.C. Martin, J. Phys. Chem. Ref. Data 34 (2005) 1559. 